\title{
Compensatory techniques on urban drainage for flood control with the aid of mathematical modelling: a case study in Rio de Janeiro City
}

\author{
M. G. Miguez, A. P. Veról, F. C. B. Mascarenhas, R. B. Santos \\ \& M. C. Martingil \\ Universidade Federal do Rio de Janeiro, Brazil
}

\begin{abstract}
The traditional canalisation approach for flood control has been complemented or replaced by new concepts that consider a systemic approach, with distributed interventions over the catchment intending to recreate flow patterns prior to the urbanisation. Compensatory techniques on urban drainage have been proposed to fulfil this aim. However, the spatio-temporal variability of the phenomenon gives particular characteristics to each catchment. In this context, a systemic evaluation of flood control projects is needed, providing adequate spatial coverage without superimposing effects in time. Mathematical modelling emerges as a useful tool to represent the integrated behaviour of urban drainage and landscape. This is where this work takes place, assessing an urban catchment subjected to floods with the aid of MODCEL, a mathematical model developed in the Federal University of Rio de Janeiro. This model represents the catchment using the flow cells concept, conforming a flow net. Guerenguê River catchment, located in the west side of Rio de Janeiro city, in Jacarepaguá neighbourhood, which is an area of particular interest because of the Olympic Games that will be held in Rio de Janeiro in 2016, was taken as a case study. This catchment suffers from serious problems related to its drainage system and water pollution, compromising the local quality of life. The starting point of this evaluation is a set of retention reservoirs, associated with an urban retrofit proposed by the Municipality. In addition, this study introduces several distributed compensatory measures in order to obtain an effective result in flood attenuation. The modelling results show that, at present situation, great part of the catchment suffers from flooding, with water depths that usually range from $0.15 \mathrm{~m}$ to $1.50 \mathrm{~m}$. In critical areas, flooding may surpass the level of $1.50 \mathrm{~m}$ high. The introduction
\end{abstract}


of the compensatory techniques is capable to change this picture significantly. However, land use control shows to be a key factor for sustainability.

Keywords: compensatory techniques on urban drainage, retention reservoirs, mathematical modelling, MODCEL.

\section{Introduction}

The traditional canalisation approach for flood control has been complemented or replaced by new concepts that consider a systemic approach, with distributed interventions over the catchment intending to recreate flow patterns prior to the urbanisation. However, the spatio-temporal variability of the phenomenon gives particular characteristics to each catchment. In this context, a systemic evaluation of flood control projects is needed, providing adequate spatial coverage without superimposing effects in time.

A fundamental tool to an integrated analysis of how complex systems work is the mathematical and computational modelling. Mathematical models can simulate the nature according to the simplification hypothesis formulated in the modelling process. If this representation is adjusted, one can afford a tool that is capable to forecast future scenarios, in differently combined situations, supporting the planning process and defining the basic configuration of design arrangements.

In the recent past decades, the problem of flooding has been discussed from a new perspective. It is considered more important to treat the problem from its source, in a systemic way, with distributed measures over the urban landscape, to reduce and delay flood peaks. This type of action seeks to restore conditions closer to those of the original natural drainage. Recent practices of drainage projects in Brazilian great cities have involved the use of the so-called Compensatory Techniques on Urban Drainage.

This work aims to evaluate the implementation of a set of reservoirs in a Community called Juliano Moreira, as proposed by the Municipality of Rio de Janeiro. Considering the obtained results, some extra reservoirs, designed by the authors, in the context of the use of compensatory techniques on urban drainage will be added. The mathematical model called MODCEL, developed in Universidade Federal do Rio de Janeiro, is used as a forecast tool. The flood problem is discussed in a systemic perspective and land use control is also addressed as a key element.

\section{Compensatory techniques on urban drainage for flood control}

Traditional practices in urban drainage tend to act on the consequences of floods, which are, in this case, the increased superficial water volumes and faster flow velocities. These practices frequently transfer problems instead of solving them. The traditional canalisation approach for flood control has been complemented or replaced by new concepts that consider a systemic approach, with distributed interventions over the catchment intending to reproduce as well as possible the 
flow patterns prior to the urbanisation. Compensatory techniques on urban drainage, a concept consolidated by Batista et al. [1] in Brazil, is an optional approach that goes towards this aim.

In the last decades, several different conceptions have been proposed with some minor differences among them. All of them, however, tend to consider these urban drainage questions in an integrated way, trying to cover natural characteristics of the hydrological cycle, while adding value to the city itself. In this context, some of these new concepts can be mentioned: Best Management Practices (BMPs), Low Impact Development (LID), Sustainable Urban Drainage System (SUDS) and Water Sensitive Urban Design (WSUD).

BMPs are designed to reduce stormwater volume, peak flows, and nonpoint source pollution through infiltration, filtration, biological or chemical processes, retention, and detention (US EPA [2]). Coffman et al. [3] proposed a design concept of Low Impact Development (LID), which adopts a set of procedures that try to understand and reproduce hydrological behaviour prior to urbanisation. LID and BMP are very often used together and may complement each other.

Another possibility of improving urban drainage solutions concerns the Sustainable Urban Drainage System (SUDS) concept. In this case, the ideals of sustainable development are included in the drainage system design process, that is, impacts on the catchment due to drainage solutions may not be transferred in space or time. Moreover, besides contributing to sustainable development, drainage systems can be developed to improve urban design, managing environmental risks and enhancing built environment. SUDS objectives account both for reducing quantity and quality problems and maximising amenities and biodiversity opportunities, which form the three way concept: quantity - quality - amenity and biodiversity. All of them have to be managed collectively and the desired solution appears in the interface of these three objectives (CIRIA [4]). The philosophy of SUDS, similar to LID, is also to replicate, as well as possible, the natural conditions of pre-development site. Moreover, this concept tends to consider the sanitation aspects in a broad integrated sense. Concerns on wastewater and solid waste management are also treated in drainage system projects.

The continuous evolution of all these concepts and the seek for new urban drainage system solution led also to the Water Sensitive Urban Design (WSUD) concept. WSUD tries to integrate social and physical sciences in a holistic management proposition for urban waters.

In Brazil, the concept developed and formalised by Baptista et al. [1], the compensatory techniques, means the introduction of several different measures, focusing on infiltration and storage capacity, with the aim of compensating urban impacts on the hydrological cycle. In this context, permeable pavements, bioretention facilities, vegetated roof covers, grass swales, dry wells, filter strips, vegetated buffers, rain barrels, cisterns, infiltration trenches, on-lot detention reservoirs, temporary storage reservoirs, reforestation, among others, may be good solutions for achieving these goals and can also integrate harmoniously into the urban environment as they can be designed as recreational areas in dry 
weather and, then, assume the characteristics of multifunctional landscapes (Miguez et al. [5]).

The integration of drainage solutions with the revitalisation and enhancement of urban space can be an important way to solve the problem of flooding, once the possibility of designing actions distributed over the entire urbanised catchment, avoiding the traditional end-of-pipe solutions, allows the optimisation of public investments in multiple purpose works and a possible better acceptance by the communities affected by the built environment improvement.

\section{Case study: the Guerenguê River catchment}

The work presented here will consider the assessment of Guerenguê River catchment, in the west region of Rio de Janeiro city, Brazil. The outfall of this catchment occurs in Jacarepaguá Coastal Lagoon System. This catchment presents large flooded areas, with irregular occupations, near riverine areas, and an advanced environmental degrading problem.

\subsection{Initial description}

The majority of the river catchment area is occupied by Jacarepaguá neighbourhood. Extensive lowlands compose the region, with hill slopes on its upper reaches. The outfall of Guerenguê River occurs in a complex of coastal lagoons. More than 500,000 inhabitants live in Jacarepaguá region, where, in social terms, human development is considered to be from medium to high. The main tributaries of Guerenguê River are Monjolo River, Areal River and Engenho Novo River, as it is shown in Figure 1.

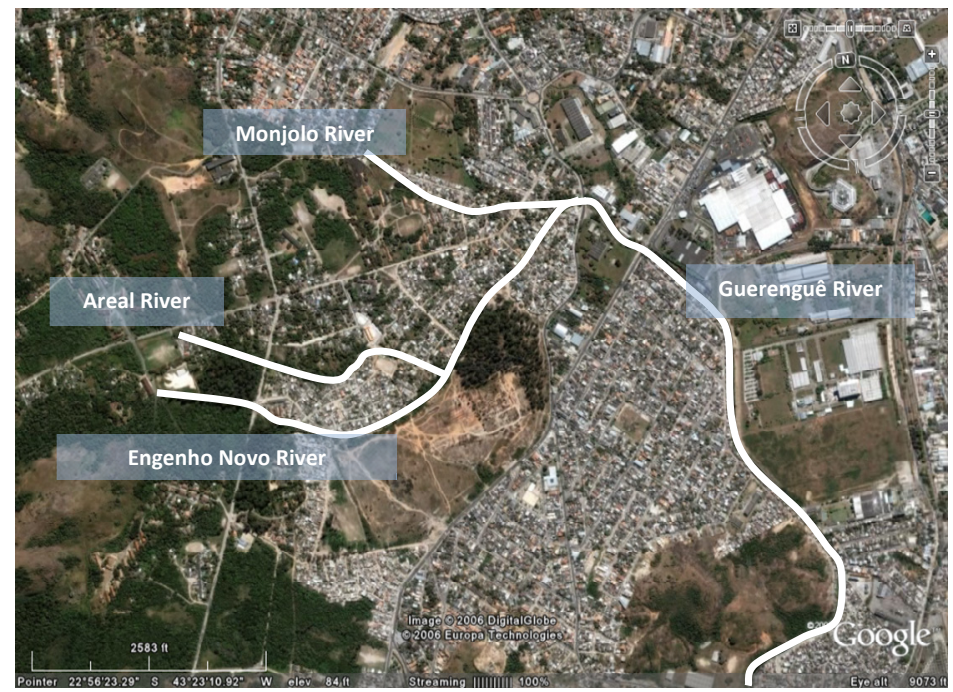

Figure 1: The Guerenguê River and its main tributaries. 
The upstream reach of Engenho Novo River is located at a park, in a preserved forest area of $411 \mathrm{~m}$ of elevation. Areal River is the first one to encounter Engenho Novo River at its left margin. Then, Monjolo River also enters Engenho Novo River, finally forming Guerenguê River. Urban occupation is increasing and there are several problems related with urban floods and sanitation aspects. Wastewaters pollute the rivers and the downstream lagoon complex suffers from eutrophication processes. The case study developed in this paper considers the retrofit of an upstream neighbourhood called Juliano Moreira.

\subsection{Relevance of the studied area}

Rio de Janeiro City was chosen in October 2009 to host the XXXI Olympic Games to be held in 2016. Considering the sport as a sponsor of social inclusion and of regional development, it is expected that there will be a further development of the city due to the magnitude of this event.

The city's image will be widely publicised and strengthened not only in America, but also around the whole world. Large investments are planned and are already being executed in order to provide the city with the required infrastructure for the 2016 Olympic Games. The construction and adequacy of sports infrastructure is scheduled for several areas of the city, but a significant amount of them will be located in the western area of Rio de Janeiro city, where the studied catchment lays.

This event will lead to changes of land use and occupation in this region, especially because it is expected a increase in the rates of population and economic growth. Though, Guerenguê River catchment will experience a process of intense modification in land use, which will put at risk important green areas, covered with natural vegetation. Considering that the process of urbanisation can significantly aggravate flooding in a catchment, it is identified here the potentiality for the application of compensatory techniques approach, to ensure a balanced growth, avoiding to worse the local environmental conditions and developing the catchment in a sustainable manner. This catchment deserves a special attention, so that the expected urban growth does not worsen the existing problems.

Some of the Municipality actions proposed for this region show concerns about the urban growth problem, and some opportunities appear in the context of urban drainage. However, it seems that there is still a lack of systemic solutions.

\subsection{Urban design actions}

Juliano Moreira is the name of a public institution created in the city of Rio de Janeiro in the first half of the twentieth century, to host those who suffered from mentally illness, but today serves as a home to hundreds of persons.

Originally located in the neighbourhood of Jacarepaguá, occupying $77 \mathrm{~km}^{2}$ of a large green area of the upstream reaches of the catchment, it officially became a neighbourhood of Jacarepaguá Administrative District in September 2009. This region was, then, included in the Brazilian Growth Acceleration Program 
(PAC [6]), allowing the community to receive infra-structure, such as paving, construction of water networks and sewage systems.

Taking the history of catastrophic floods in the community into account, the Municipality proposed a restructuring project, providing the creation of detention reservoirs associated with the canalisation and restoration of river reaches. The project also includes the removal of illegal buildings in marginal areas of the rivers and relocating families within the community.

The restructuring of the Community, includes interventions in the infrastructure, urbanisation, housing and land tenure, reaching a population of about 20,000 people. The whole project is estimated at approximately 55 million euros.

The proposed reservoirs and total and partial rectifications of rivers can be observed in the schematic drawing presented in Figure 2.

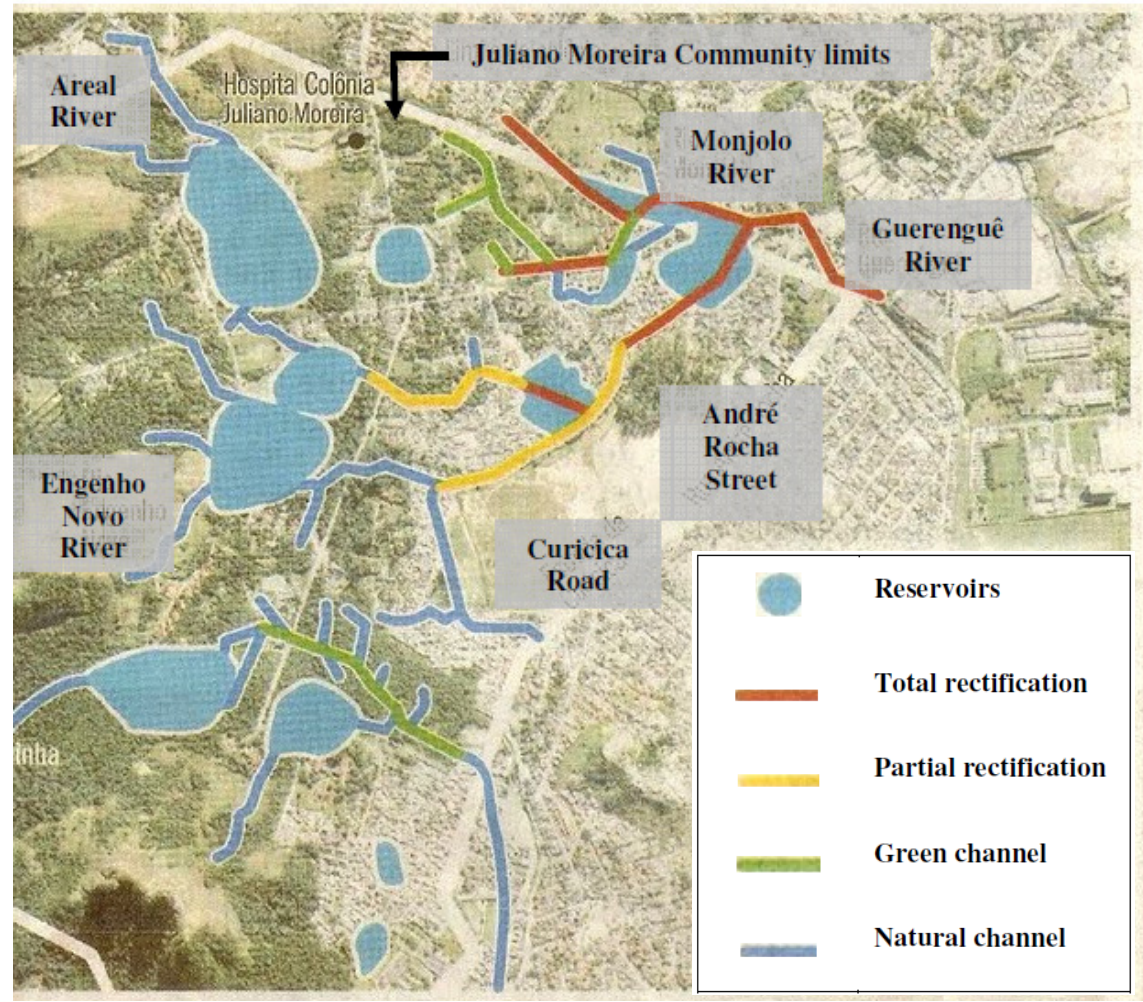

Figure 2: Rio de Janeiro municipality proposal for Juliano Moreira community (O Globo [7]).

It is important to recognise that this is an important public initiative, but yet developed in a local basis. The downstream reaches of the catchment are suffering with a great housing market pressure and there is still a lack of control 
on imperviousness rates and the use of landfills on lowlands areas. There are also several other irregular habitations on risk areas along riverbanks.

\subsection{Simulation scenarios}

The study developed here intends to simulate the present situation of the catchment, to establish the reference for comparisons. In the sequence, the proposition of the Municipality for Juliano Moreira Community is simulated. Based on these first results, some complementary actions, also based on the compensatory techniques approach, are proposed, considering the availability of open spaces in the catchment. The criticality of flooding problems in the catchment arises in these scenarios and this will be the stage for the discussion developed in this paper.

\subsection{Mathematical modelling}

In the context of the present work, it is essential to reproduce the situation of surface flows integrated with the urban drainage system and the urban solutions proposed by the Municipality for the region.

For this purpose, it was used MODCEL (Mascarenhas et al. [8]; Mascarenhas and Miguez [9]; Miguez [10]), a hydrodynamic computer model that allows an adequate representation not only of the channel flows, but also of the runoff over flood plains in urbanised areas. This model is able to represent the various interactions and the future interventions in the region, even when dealing with urban design outside the drainage system.

The results obtained for the simulated scenarios allow a comparatively evaluation, verifying the effect obtained with the proposed measures. 157 cells were used by the mathematical model, comprising channel cells, natural and urbanised superficial cells and reservoir cells. The main link used in the flow net was the Saint-Venant dynamic equation.

The recurrence time adopted for calculating the design rainfall was 20 years and the duration of the rain coincides with the critical time for the Guerengue River catchment, which was 225 minutes. Downstream coastal lagoon system was considered with its higher level, as a boundary condition.

The calibration process for this simulation considered an alternative approach. There was not available simultaneous information of rainfall and water levels in the main rivers. However, a flood map, with water levels in the flood plains, was available. This map was constructed based on two previous major events. Considering this information and assuming that the design rainfall of 20 years of recurrence time is of similar magnitude of the observed events, the model was adjusted to approximately represent the available flood map. Table 1 shows the results of the calibration process for the considered control points. Figure 3 shows the representation of the modelled present situation.

As expected, the modelled results show an unfavourable situation in the region, with water levels above $1.5 \mathrm{~m}$ in the middle Guerenguê River and several other points with significant flooding distributed throughout the catchment. 
Table 1: $\quad$ Calibration results.

\begin{tabular}{|c|c|c|}
\hline Site & $\begin{array}{c}\text { Target water } \\
\text { depths } \\
(\mathrm{m})\end{array}$ & $\begin{array}{c}\text { Calibrated } \\
\text { water depths } \\
(\mathrm{m})\end{array}$ \\
\hline Castor Street - Bandeirantes Road & $0.30-0.50$ & 0.21 \\
\hline Castor Street - Floreal Street & $0.75-1.00$ & 0.90 \\
\hline Vila Aurora Street - André Rocha Street & $1.00-1.50$ & 1.59 \\
\hline Guerenguê Road - Beira Lima Avenue & $0.15-0.20$ & 0.30 \\
\hline Onil Machado Gitahy Street - Clodomir Lucas & $0.75-1,00$ & 0.90 \\
\hline dos Reis Street & & 0.36 \\
\hline Coronel Willyan Street - Clóvis da Silva Street & $0.30-0.50$ & 0.43 \\
\hline Aires Ferreira Street & $0.30-0.50$ & 0.66 \\
\hline Outeiro Santos Road - Luciano de Rose Street & $0.75-1.00$ & 0.65 \\
\hline \multicolumn{2}{|r}{} & \\
\hline
\end{tabular}

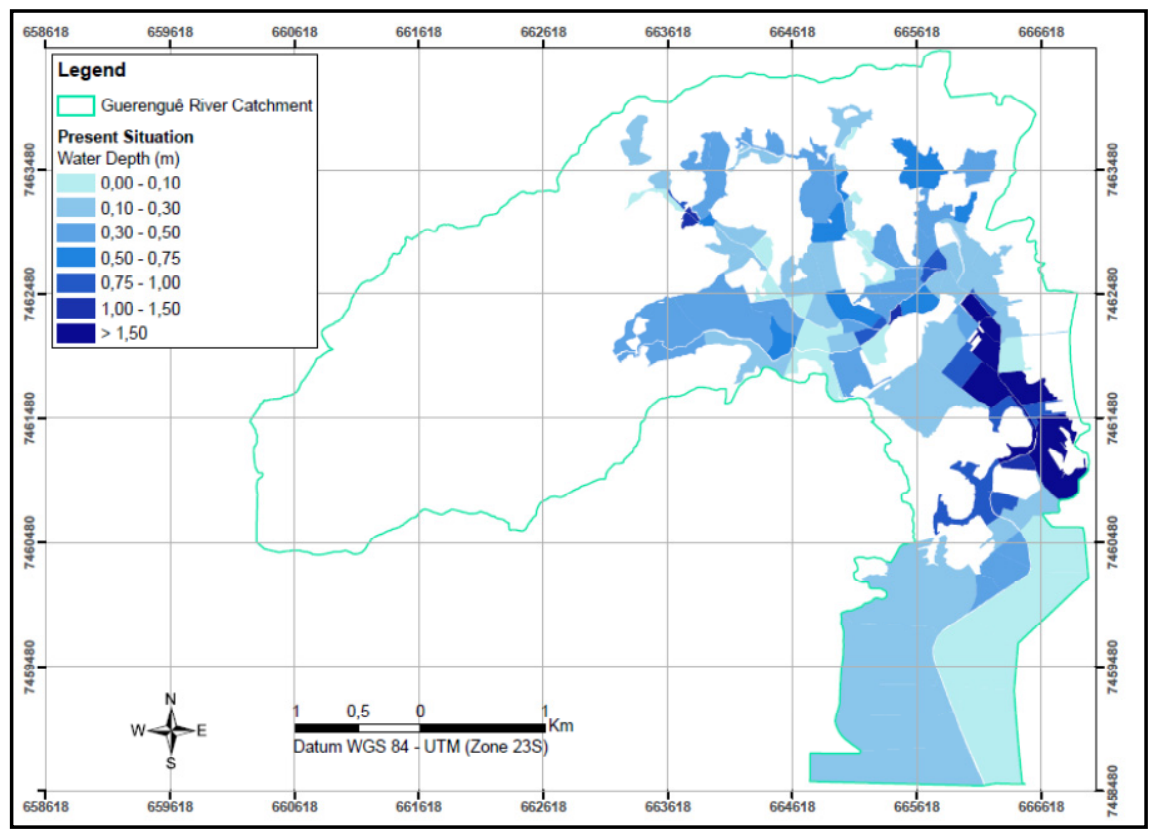

Figure 3: $\quad$ Present situation flood map.

In the following simulation step, the reservoirs proposed by the Municipality of Rio de Janeiro for Juliano Moreira Community, shown in Figure 2, were 
introduced in the model. Altogether, they have an approximate area of 33 ha. The retention reservoirs proposed by the Municipality, with a permanent pool, were assumed with their bottom elevation equal to the nearest river reaches modelled. When the reservoirs did not communicate to any river stream, their depths were considered equal to $1.0 \mathrm{~m}$.

The results obtained in this scenario are presented in the Figure 4.

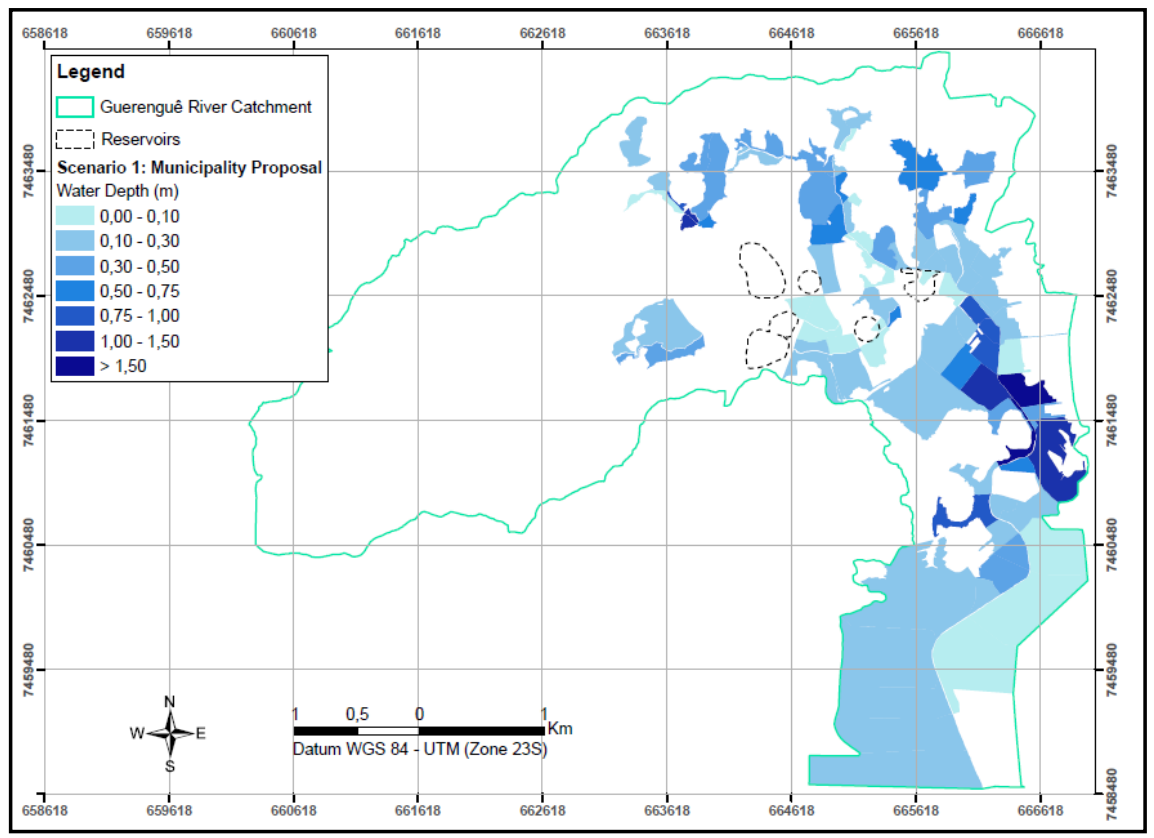

Figure 4: $\quad$ Municipality proposal flood map.

Taking the two flood maps into consideration, it is possible to notice a significant decrease in flood levels in areas around the reservoirs and some reduction in the downstream water levels. This result show the right choice for the new urban development expected for this region. This contribution, however, do not solve the problem of lower catchment areas, making it necessary to include other compensatory measures distributed over the catchment to reduce flooding.

With the aid of satellite images, it was possible to identify other areas of interest capable to receive flood control measures.

A set of measures, including new reservoirs distributed over the catchment, removal of marginal occupation and decrease of some squares elevation, was proposed and introduced in MODCEL, complementing the effects of the Municipality project. The new reservoirs were designed following the same idea of the previous scenario. Figure 5 presents the additional proposed reservoirs and

Figure 6 presents two of the chosen areas in detail. 


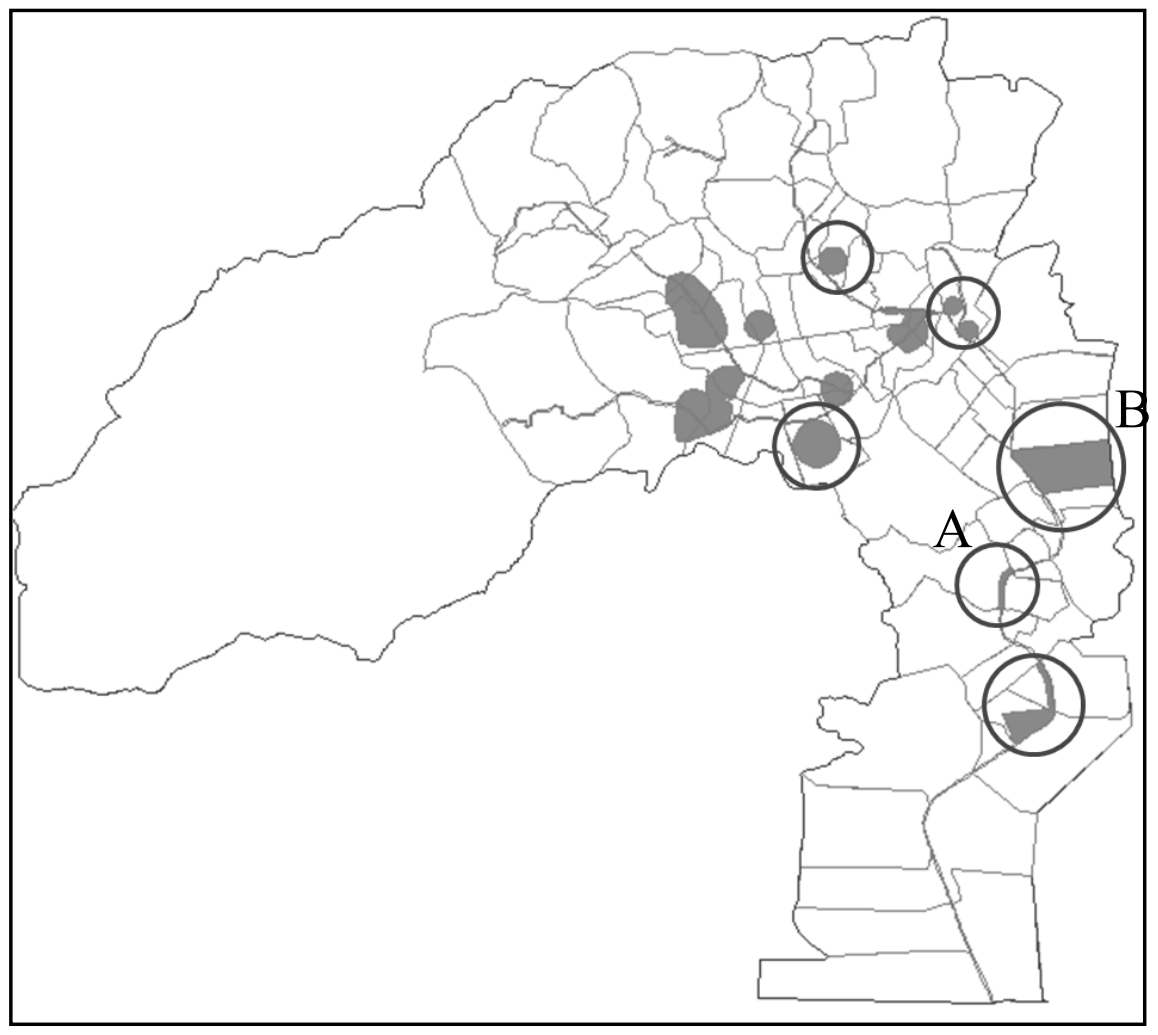

Figure 5: $\quad$ Additional reservoirs proposal.

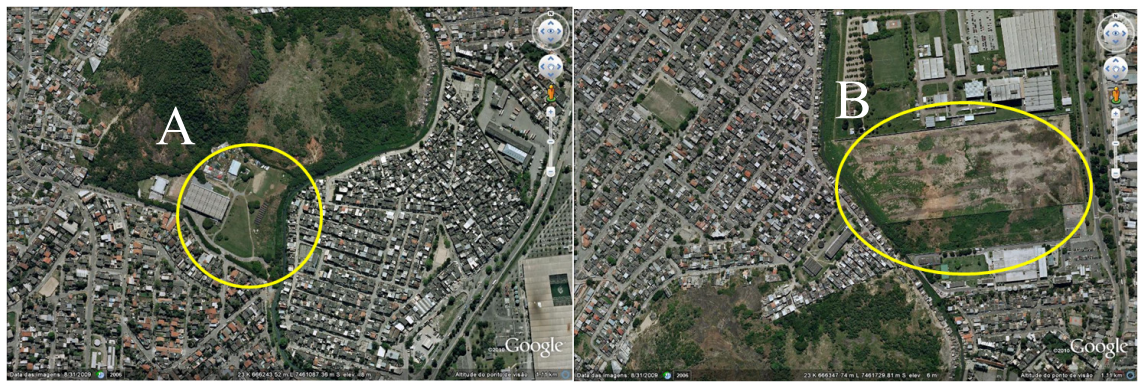

Figure 6: Two of the chosen areas to receive measures - A: marginal protections; B: reservoirs.

The results of this new scenario, considering the additional reservoirs, are shown in the flood map presented in Figure 7.

It was observed a greater improvement, resulting in a general flood reduction, with the introduction of the additional reservoirs. It is important to notice that even some areas of Juliano Moreira Community presented a larger decrease in water level when compared to the previous scenario (Municipality proposal). 


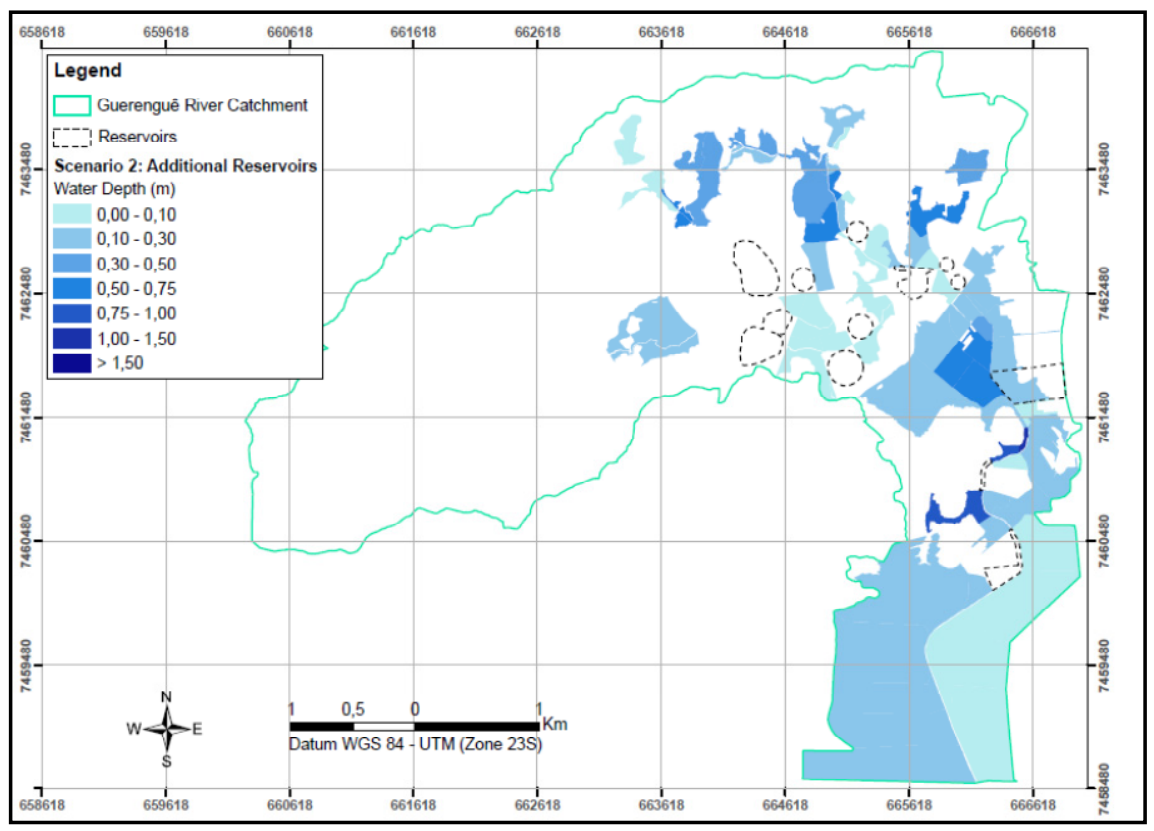

Figure 7: Additional Reservoirs flood map.

This result emphasises the importance of the spatial distribution of the interventions over the catchment. However, some regions still present high water depths, which show the need for additional compensatory techniques to solve the problem. It is important to stress that micro-drainage problems were not treated in these simulations and some flooding problems are clearly related with this question, once it is noticed that there are flooded areas not directly related to the macro-drainage system. Downstream areas, near the outfall at the coastal lagoon system, are less sensible to changes in flow patterns. These are very low areas that are being raised for new housing enterprises in a very risky process. Therefore, another important question is that even with a set of several reservoirs distributed over the basin, flooding still occurs in the modified situation and housing pressures are high. This result strongly points to the need of urban land use control on future developments, in order to minimise flow generation.

\section{Concluding remarks}

This paper aimed to show a discussion on urban drainage solutions for flood control, using a case study related to a developing region in Rio de Janeiro City. Departing from a Municipality proposition for a new urban development in Guerenguê River catchment and considering the concept of compensatory techniques applied to urban drainage, a set of simulation scenarios was constructed in a mathematical model representation, ranging from the present 
situation to the Municipality proposal and a complementary set of measures distributed over the entire catchment.

The obtained results show the importance of considering systemic actions, aiming to recover lost hydrological functions in the urban environment. In this context, the use of reservoirs of several types, in different scales, is very important. However, it is important to stress that real sustainable drainage solutions need to be considered together with land use control. Urban development changes the urban water cycle and this effect must be treated in an integrated way with urban drainage design in order to produce effective solutions along time.

\section{Acknowledgement}

The authors acknowledge CNPq for the scholarships.

\section{References}

[1] Batista, M.; Nascimento, N. \& Barraud, S. Compensatory Techniques on Urban Drainage. ABRH: Porto Alegre, Brazil, 2005. (in Portuguese).

[2] United States Environmental Protection Agency - US EPA. The Use of Best Management Practices (BMPs) in Urban Watersheds, by Muthukrishnan, S.; Madge, B.; Selvakumar, A.; Field, R.; Sullivan, D. EPA/600/R-04/184S, 2004.

[3] Coffman, L.S., Cheng, M., Weinstein, N. \& Clar, M. Low-Impact Development Hydrologic Analysis and Design. Proceedings of the 25th Annual Conference on Water Resources Planning and Management, Nova York, USA, 1998.

[4] CIRIA. The SUDS Manual, by Woods-Ballard, B.; Kellagher, R.; Martin, P.; Bray, R.; Shaffer, P. CIRIA C697, 2007.

[5] Miguez, M.G.; Mascarenhas, F.C.B.; Magalhães, L. P. C. Multifunctional landscapes for urban flood control: the case of Rio de Janeiro (Chapter 2). Flood Prevention and Remediation, ed. Mascarenhas, F.C.B., WIT Press: Southampton, Boston, pp. 33-52, 2011.

[6] PAC, www.brasil.gov.br/pac.

[7] O Globo, www.oglobo.com.br.

[8] Mascarenhas, F.C.B.; Toda, K.; Miguez, M.G.; Inoue, K. Flood Risk Simulation. WIT PRESS: Southampton and Boston, 436p., 2005.

[9] Mascarenhas, F.C.B.; Miguez, M.G. Urban Flood Control through a Mathematical Cell. Water International, 27; pp. 208-218, 2002.

[10] Miguez, M. G. Flow Cell Mathematical Model to Urban Catchments. D.Sc. Thesis. Universidade Federal do Rio de Janeiro. Rio de Janeiro, RJ, Brasil. 301p. 2001 (in Portuguese). 